that it produces compulsive sexual activity in male animals from the experiments by Ferguson et al, 1 Tagliamonte et $a l^{2}{ }^{2}$ Shillito et $a^{3},{ }^{3}$ and Gessa et $a l^{4}$ The specificity of this action is demonstrated by the fact that the sexual excitement induced by PCPA is inhibited by administration of 5-HTP. Gessa and Tagliamonte ${ }^{5}$ have hypothesised a disturbance of 5-hydroxytryptamine (5-HT) as the causal element in sexual dysfunctions. Patients with multiple sclerosis treated by Hyyppa ${ }^{6}$ with Ltryptophan did not show any significant change in sexual motivation. Hyyppa et al ${ }^{7}$ also administered the amino-acid to normal volunteers, and although no change in sexual behaviour or arousal was noted, transient decreases in plasma gonadotrophins were found after each dose. Finally, Sicuteri et al ${ }^{9}$ observed that L-tryptophan was capable of diminishing excessive sexual responsiveness in patients suffering from hypersexuality.

It is is difficult, therefore, to understand the cause of the hypersexuality seen after Ltryptophan in Drs Egan and Hammad's patients. It should be noted, however, that four out of five of them were suffering from schizophrenia and were being treated with phenothiazines in addition to the amino-acid. Bender ${ }^{9}$ has observed that phenothiazines have a complex action on serum tryptophan in schizophrenics; it appears that in such patients they reduce brain serotonin synthesis, whereas in rats they have the reverse effect. It might be postulated that, in similar fashion, administered L-tryptophan may have an atypical effect in schizophrenic patients receiving phenothiazines.

L-Tryptophan has so far been mainly indicated for the treatment of affective disorders and we believe that it has been used very little in the management of schizophrenia. Smuthies ${ }^{10}$ has recently drawn attention to its possible application in schizophrenic patients. If his advice is followed hypersexuality may become a more commonly reported side effect.

ALAN D BRoADHURST BAPUjI RAO

West Suffolk Hospital,

Bury St Edmunds

' Ferguson, J, et al, Psychophysiology, 1969, 6, 221.

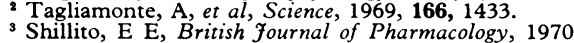
38, 305.

- Gessa, G L, et al, Nature, 1970, 227, 616 Pharmacolognd Tagliamonte, A, Sexual Behaviour: Pharmacology

Hyyppa, M T, British Medical fournal, 1976, 2, 1073 Hyyppa, M T, et al, Presentation at International Congress of Pharmacology, Helsinki, 1975.

Sicuteri, F, et al, Presentation at International Congress of Pharmacology, Helsinki, 1975.

10 Bender, D A, Lancet, 1976, 2, 427.

\section{Community self-care}

SIR,-For the past two or three years we have had a community care scheme which, is organised by the local inhabitants. It has provided a great deal of help in our practice in that there is a panel of volunteer drivers who will take visitors to hospital, collect prescriptions for the housebound, and also bring patients to the health centre and even provide immediate companionship in a family crisis.

We try to make reasonable use of their services and not abuse them. The local people are encouraged to offer their services for driving, gardening, phone-answering, etc. There is a phone number (easily remembered) to be used for offers and requests. It is not intended as a "them and us" arrangement but one in which there are times for giving help and times for receiving it (in one form or another). Finally, it is not used as a system for avoiding proper medical responsibilities but as an aid to improving care. It is known as LINK (presumably "the bond between").

The details are beyond the scope of a shor letter, but further inquiries are welcomed.

\section{R J COCKeriLI}

The Health Centre,

Oxted, Surrey RH8 0BQ

\section{Ferrous sulphate: danger to children}

SIR,-We were disappointed to receive a recommendation from the DHSS recommending the use of ferrous sulphate. The British National Formulary 1976-1978 is quoted as saying: "The dosage of elemental iron should be at least $100 \mathrm{mg}$ daily. Ferrous sulphate in tablet form is the preparation of choice."

Although ferrous sulphate is the cheapest iron preparation, it is also the most toxic. The green, sugar-coated tablets attract small children, who may suffer haemorrhagic necrosis of the gastric or jejunal mucosa, live damage, and sometimes death after swallowing them. A very common sequence is that the toddler gains access to his mother's iron tablets, prescribed for her when she is pregnant again.

In 1966 four infants under 3 years of age were admitted to our children's ward with ferrous sulphate poisoning. All were the offspring of our antenatal patients. Three were severely shocked and had gastric haemorrhages and one was left with an hour-glass constriction of the stomach. The ferrous sulphate tablets had been dispensed with a warning in red on the bottle that the tablets were dangerous to children.

Since 1967 the prescription of ferrous sulphate for pregnant women has been forbidden in our obstetric depaitment and local general practitioners have been encouraged to use other preparations. Between January 1967 and December 1975, of 16 children admitted after ingesting iron tablets only three had taken ferrous sulphate and no case was severe.

We are convinced that, at least for pregnant women with young children, it is wise to avoid prescribing ferrous sulphate.

J R SAUNDERS

Department of Obstetrics and A W FERGUSON

Paediatrics, Bedford General Hospital Bedford

\section{FEIBA in haemophiliacs with factor VII} inhibitor

SIR,-Dr G D O Lowe and others (6 November, p 1110) report the successful use of prothrombin complex to secure haemostasis in haemophiliac with an inhibitor to factor VIII. Others have used "factor VIII inhibitor bypassing activity" (FEIBA) in such patient with apparent success, ${ }^{12}$ prompting us to report our experience with this product.

A 32-vear-old man sustained extensive anterior myocardial infarction in 1975. Intractable angina of effort developed subsequently and coronary arteriography revealed stenosis of the anterio descending branch of the left coronary artery. Femoral arterial puncture for this procedure led to extensive bruising of the groin and thigh. Excessive bleeding had also occurred after dental extractions in 1967. Coagulation screening revealed a prolonged activated partial thromboplastin time (APTT) of $70 \mathrm{~s}$ (control $34 \mathrm{~s}$ ) with an otherwise normal profile. The prolonged APTT showed little correction in mixing tests with normal plasma, suggesting the presence of a rapidly acting inhibitor. Levels of all recognised clotting factors were normal when assayed at high dilution.

The APTT of plasma containing moderate numbers of platelets shortened during standing at room temperature for several hours; the association between platelets and the contact phase of coagulation led us to investigate the possibility that the inhibitor might be an abnormal variant of the physiological "anti-Xla." 3 We found that the inhibitor could destroy contact activation product prepared from the patient or from normal subjects very rapidly; it differed in many respects from physiological "anti-Xla."

It seemed likely that FEIBA would bypass the activity of this inhibitor. A trial dose of $15 \mathrm{U} / \mathrm{kg}$ body weight was given. The APTT shortened by $12 \mathrm{~s}$ and this effect lasted at least 72 hours, without evidence of intramuscular coagulation. At operation a vein graft was used to circumvent the stenosis under cardiopulmonary bypass. While on bypass the patient was partially exchangetransfused with six units of bank blood. During closure, after heparin neutralisation, FEIBA $40 \mathrm{U} / \mathrm{kg}$ was given together with fresh blood, platelet concentrate, and fresh frozen plasma. Excellent haemostasis was achieved, with complete normalisation of the APTT, again without evidence of intravascular coagulation although the contribution of FEIBA to haemostasis is uncertain. Postoperative recovery was uneventful and in the four weeks since surgery the APTT has risen slowly to $70 \mathrm{~s}$.

We will report this case and the properties of the unusual inhibitor in more detail elsewhere.

We thank Mr D Ross, who kindly gave us permission to report this case.

TREVOR THOMAS Hugh Williams YVONNE WILLIAMS JILL HUNT

Department of Haematology, Guy's Hospital,

${ }^{1}$ English, P J, Sheppard, E M, and Wensley, R T,
Lancet, 1976, 1, 1299.
${ }^{2}$ English, P J, Sheppard, E M, and Wensley, R T,
Lancet, 1976, 2, 207.
${ }^{3}$ Nossel, H L, and Niemitz, J, Blood, 1965, 25, 712 .

Low molecular weight dextran

SIR,-While in agreement with three of the rules quoted by Dr T G Feest (27 November, $\mathrm{p}$ 1300) for the use of low molecular weight dextran (LMWD), I would disagree with the fourth. He states that LMWD should not be infused at a rate faster than 11 /day. However, this would exclude the very useful effect of dextran 40 in patients who have polycythaemia secondary to chronic hypoxic lung disease, as reported by Harrison et al. ${ }^{1}$ This technique involves withdrawing 21 of blood in $1 \mathrm{~h}$ and giving 11 of dextran 40 simultaneously and another 1 l over the next 6-8 h. This has great symptomatic benefit for secondarily polycythaemic patients, reducing their packed cell volume (PCV) to near normal levels for as long as six months, when the procedure may be repeated. Not only are headaches and lethargy improved, but also pulmonary artery pressure may be reduced and thus right ventricular strain. It has been shown experimentally in dogs that the pulmonary vascular resistance rises exponentially with a rise of PCV. ${ }^{2}$ Simple venesection without dextran 40 may lead to an increased risk of clotting. 
The benefits of reducing the PCV in such patients are surely far greater than the slight risk of acute renal failure, provided that polycythaemic patients with evidence of impaired renal function are excluded from such therapy.

David Honeybourne

Regional Respiratory Laboratory,

Brook General Hospital, ' Harrison, B, et al, British Medical fournal, 1971, 4,
713.
'Agarwal, J B, et al, fournal of Applied Physiology,
1970, 29, 866.

\section{BMA representation in hospitals}

SIR,-Some hospital doctors seem to have a feeling all is not well with the BMA's arrangements for representing them. This at any rate is the usual excuse given for non-membership. We feel at Moorfields that it is time that some sort of reorganisation of the hospital section of the BMA was made, especially in regard to there being a BMA "presence" at hospital level or at least some sort of forum for medicopolitical discussion among hospital doctors.

We share the view of the Secretary (17 July, $\mathrm{p}$ 190) that the formation of splinter groups may not be helpful. The BMA exists as our representative body, it has a well established secretariat, good premises, and a large membership; above all, it includes as members our general practitioner colleagues. It seems both unnecessary and undesirable to set up a rival organisation of hospital doctors only, a stratification which incidentally may have less and less meaning in the future if GPs become more concerned with hospital work.

Accordingly, therefore, we have set up an organisation in our hospital which we call the "Moorfields Doctors Group." The purposes of this group are, firstly, to elect representatives to the Regional Committee for Hospital Medical Services and, secondly, to discuss medicopolitical matters and make our views known. The group is emphatically not a splinter organisation but is a forum in which matters can be discussed. It includes all doctors working regularly in the hospital regardless of seniority.

We would commend other hospitals to consider setting up similar groups. We understand that discussions are going on for the strengthening of the links between hospital medicine and the BMA. We certainly welcome this and are convinced that in order for it to be successful there must be a suitable organisation at the hospital level.

REDMOND SMITH

London

\section{A "specialist" grade}

SIR,-During the past three years my job as a postgraduate dean has given me unique opportunities to discuss careers and career prospects with doctors in all branches of medicine. With the exception of about a couple of junior doctors, I have not yet met a single doctor (with whom I have discussed the problem) who does not believe that the DHSS must establish a service grade between registrar and consultant.

The term "subconsultant" is an unattractive one but I can see no reason why we cannot have "specialists" and "consultants" as in the Army and similar to the grades in the Public
Health Laboratory Service. There is no reason why, for some, the "specialist" grade could not still be a career grade and a stepping stone to a consultant post. For others it would provide a permanent and dignified service position in the Health Service. There are, I believe, quite a number of doctors who would welcome the type of service job which a "specialist" grade would offer. Such a "specialist" grade could make it possible to dispense with medical assistant, clinical assistant, and perhaps also the hospital practitioner grade. It would also solve the problem of many doctors, including those with domestic ties, who have undergone retraining and by whom consultant posts are often difficult to obtain.

I am told that objection to the "subconsultant" grade has come from the hierarchy of the profession and not from the Department. I think that it is time that the manpower experts of our profession had a new look at the grades of doctors employed in the hospital service. The establishment of a "specialist" grade could resolve some of the difficulties of service $v$ higher specialist training and could also perhaps readily fit the EEC requirements. The formation of such a grade could, in my opinion, do nothing but improve the job satisfaction and status of many doctors, including that of consultants.

Rowhook Medical Society,

GeORGE Dick

The Chequers Inn,

Rowhook,

Horsham, w Sussex

\section{Consultants' contract}

SIR,-The Lancashire Area Consultants' Committee, representing some 300 consultant in six districts, discussed the new contrac proposals and were unanimous in their suppor of the principle of a standard working week defined in flexible notional half days plus extra remuneration for emergency re-call, domiciliary consultations, category II work, and family planning.

The proposals of the BMA and the Hospital Consultants and Specialists Association are essentially the same, and it is hoped that the two associations will co-operate and produce as a matter of urgency a joint strategy which will have the support of the vast majority of consultants and will assure acceptance by the DHSS.

We believe that this is the only way to redress the present anomalous position of consultants in the NHS, to restore a reasonable differential, and to prevent the threatened exodus of younger consultants and senior registrars to the Continent.

G BEHR Chairman,

Department of Pathology

Burnley General Hospital,

Lancashire Area Burnley, Lancs

SIR,-It is clear that the consultant body is moving away from its traditional professional attitudes and is now clamouring for a closed contract. It is claimed that this is the only "politically realistic" method of obtaining a significant increase in remuneration. We believe, however, that any gains will be shortlived and that such a contract would have major long-term disadvantages for the profession.

The junior hospital staff obtained a sub- stantial increase in earnings during the first stage of this Government's anti-infiation policy largely because the price of the new contracts was not widely known beforehand. The gains (however well deserved) were certainly outside the intent of the Government's policy and it is very unlikely that the same tactic of altering contractual arrangements will work a second time to bring about an increase in the average earnings for consultants. Even if changing to a closed contract did produce an increase in earnings we feel convinced that such an increase would quickly be eroded. It is therefore doubtful if more money will be available for consultants and very doubtful whether any increase will be lasting. By contrast the quid pro quo in the negotiations-the surrendering of some professional freedom-seems both certain and permanent. We are concerned that so little attention is being paid to this freedom and feel that consultants may be seriously undervaluing it.

The consultant at present has a very considerable degree of professional freedom. He has the freedom to manage patients without constraints other than those imposed by the ethical standards of his profession and certain financial restrictions. $\mathrm{He}$ has the freedom to allocate his time to clinical work, teaching, research, or other activities without interference from his employing authority. He has considerable freedom in the regulation of the routine clinical demands made upon his services and has always responded to this freedom by a commitment to meeting unheralded clinical need as it arises.

The adoption of any closed contract under which payment is made for quantified work will inevitably lead to progressive erosion of these freedoms. Consultant duties will be specified in detail, the numbers of patients seen, treated, and discharged will be regulated by departmental norms, and constraints will be placed on clinical freedom. The consultant will be forced to organise the balance of his work with one eye to keeping up appearances so as to be able to attract a reasonable income; the temptation to generate work for work's sake may prove irresistible. He may find himself constantly applying to the administration for recognition of certain of his activities as rewardable by additional notional half-days (NHDs). There will be scope for invidious local competition between consultants for any limited funds available for extra NHDs and of course the constant threat of some NHDs being withdrawn or transferred by some reviewing committee. In addition, the Government will have been provided with the mechanism for reducing the number of paid sessions at times of economic difficulty and thus creating underemployment.

The proposed contract will prove particularly unsatisfactory to consultants in certain specialties such as pathology and radiology where the nature of the work permits little scope for working extra hours for extra NHDs. This will lead to divisive interspecialty grievances and in the long term to a drastic fall in recruitment to some specialties, with far-reaching effects on the nature and standards of hospital medicine as a whole. This "side effect" of the proposed contract upon certain specialty groups is fairly widely understood but we would like to draw attention to another group likely to be adversely affected-consultants in teaching hospitals. The contribution made by this group to undergraduate and postgraduate teaching, research, and national administration is already seriously undervalued. It is widely assumed that teaching hospital staff are rewarded for these activities-but the truth is that they are at a financial disadvantage compared with their regional colleagues.

(a) Merit awards-It is true that the majority of merit awards are distributed to teaching hospital 